\title{
LA IMPORTANCIA DE LA TRANSMISIÓN ORAL PARA LA CREACIÓN DEL SUJETO FEMENINO
}

\author{
THE IMPORTANCE OF ORAL TRANSMISSION ON THE CREATION OF THE \\ FEMALE SUBJECT
}

\author{
Magdalena Suárez Ortega \\ Universidad de Sevilla
}

\section{Resumen:}

Este trabajo tiene como objetivo principal analizar cómo se construye la identidad femenina a través de la transmisión oral, tomando como protagonista a Concha. De esta forma, asistiremos a la evolución de este personaje en una búsqueda de la identidad personal con la ayuda del propio proceso oral.

\section{Palabras claves:}

Femenino, Concha, mujer, vida..

\section{Abstract:}

This work aims to analyse how female identity is built throughout oral transmission, with Concha as main character. In this way, we will observe the evolution of this woman in a search of the personal identity with the help of the own oral process.

\section{KEY WORD:}

Female, Concha, woman, life. 
Balbuceo del ser al no ser. El texto tiene que ser mero trasunto de esa elaboración escondida. Sacar algo del caos es, claro, traicionar es caos. La sangre hecha cuento. La oscuridad hecha luz. La vida hecha palabra. La palabra es de distinta etiología es un tratamiento mucho más lento y apagado que el de llorar o emborracharse bañarse en el mar. Es como esas inyecciones escalonadas de arfos progresivo que bañarse en esivo que hacen efecto poco a poco. Pero es el único instrumento que tenemos. Y, aunque de caracter tan diferente a aquello sobe lo que se opera, a la larga inyecta vida en la vida -otra clase de vida-, la rectifica, y nos salva de su ahogo (Carmen Martín Gaite, 1997:26-27)

\section{INTRODUCCIÓN Y JUSTIFICACIÓN}

Quizá hablar de la vida de una mujer no adquiere valor para muchas o para muchos. Sobre todo, si desde la comunidad científica se considera el contar y el decir como algo sin validez y sin fiabilidad. Éste es el primer cuestionamiento que me planteé a partir del contacto con grupos de mujeres cuyas preocupaciones existenciales se centraban en su vida laboral ${ }^{1}$ tras muchos años dedicadas a tareas reproductivas relacionadas con el cuidado de la vida.

En estos momentos me surgen dudas, cuestionamientos o interrogantes, tanto transmitidos desde los deseos e inquietudes de las propias mujeres que participan en la investigación, como de mí misma y de nuestra relación mediadora durante todo el proceso de investigación seguido. Es importante desde esta línea el valor del lenguaje, de la palabra y del contar. Ello radica, precisamente, en que la lengua tiene vida y no sólo en lo que estas mujeres dicen y cuentan sino en la manera en que lo hacen. Todo ello va asociado a la palabra, la forma de expresión, los gestos, el tono de voz, el lenguaje que transmiten sus cuerpos, su sonrisa o su seriedad, y/o la firmeza o titubeo en la expresión.

Estos aspectos me llevan a mi interés por analizar la oralidad y la escritura, todo afianzado por lo que he trabajo de este tema con diferentes profesoras del Máster sobre Estudios de la Diferencia Sexual (Grupo de Investigación DUODA, Universidad de Barcelona) (Rivera, 2002-2003; Wilson, 2003-2004; Varela, 2003-2004) y a través de las mujeres autoras cuyas obras he leído (Martín Gaite, 1974; 1978; 1993; 1997; Ferré, 1992; Librería de mujeres de Milán, 1987; Rivera, 1994). Unido a la escritura, este trabajo me sugiere diferentes aspectos. En primer lugar, a través de ella podemos observar una deseada transformación en las mujeres, como ocurre en la vida de la protagonista de este trabajo "Concha"

1 Este trabajo de investigación lo llevé a cabo para el primer módulo del máster. Por lo que éste, para mí constituye su continuidad y el marco de referencia previo o punto de partida, teniendo sentido desde los aprendizajes globales aportados por estos estudios

2 Utilizamos este pseudónimo por deseo explícito de la protagonista.
Esta transformación por la que ella pasa puede transcurrir por ese paso transitorio, por ese derrumbamiento al que alude Lessing (www.Lessing.redmood.com), pero donde al final se ve la luz. Una luz que no es otra que un nombrar, un significar desde un nuevo orden, el orden simbólico de la madre, que pasa por partir de sí, partir de la experiencia propia y situarnos en el origen de las cosas.

En segundo lugar, la escritura, pone en relación la palabra de la protagonista, la cual media con la mía. Éste es para mí el instrumento de búsqueda de sí, mío a través de Concha, y de Concha -algo menos consciente- a través de mí. Para ella le sirve de ayuda, de liberación, desde el encuentro o disponibilidad a través de mí de unos espacios y tiempos propios, para sí, que nunca ha tenido. Estos tiempos y espacios le posibilitan libertad femenina.

La escritura es la expresión de mi relación con la protagonista. El ponerse en relación una nueva mujer a través de estas palabras transmitidas y creadas por otra. Es todo un proceso de identificación y nombrar en mundo en femenino (Rivera, 1994). Sin embargo, creo que en el camino se queda mucho. Es decir, creo que en el texto se pierden muchas cosas, que Concha ha transmitido oralmente. De ahí el peso del lenguaje simbólico. En la investigación se ponen de relieve elementos que tienen un peso simbólico, desde el imaginario construido para las mujeres y en base al sistema patriarcal, y que aquí se pretende hacer reflejar mediante la escritura. Me refiero, por ejemplo, al casamiento, al nacimiento, a ese sentirse como extranjera en su propia casa, o por las relaciones que mantiene con su propio marido.

La introducción a este trabajo no tendría sentido sin situarme yo misma en él. Esto lo hago a través de dos aspectos que considero importantes; uno como autora del texto construido desde y a partir de la transmisión oral y otro, y más importante, desde ese poner-nos en relación ambas mujeres. En primer lugar desde mis definiciones $\mathrm{y}$ apreciaciones sobre la escritura y la lectura femenina. En segundo, sobre mi posicionamiento en esta investigación. Ambos aspectos son esenciales para los estudios de las mujeres, pues la inter-acción implica un poner-nos en relación para transformarnos. Sólo a partir de estos marcos de referencia podemos intentar el cambio, que pasa por un proceso de interiorización de cada una, esa interacción con las otras y el establecimiento de redes femeninas (también masculinas), que llevan al progreso social.

La escritura para mí significa un ponerse en relación con la escritora. Ello se realiza en un proceso de lectura y escritura, que es el realizado por mi parte a transmitir, sistematizar y analizar, e intentar reflejar los momentos vividos con Concha. En este sentido, es importante la relevancia de la lectura y la escritura femenina, pero no de cualquiera. Se pone el acento en las formas en que leemos y en que escribimos, así 
como en lo que significan estas acciones desde la mujer que la realiza o la interlocutora que lee o interpreta la palabra escrita que transmite la otra (Epiney-Burgard, 1998).

La lectura es cambiante, y aunque el escrito sobre Concha permanezca estable, es precisamente la interpretación, el contexto, el escenario, el tiempo o el momento personal, político o social en que ésta es leída o analizada. Su acompañamiento es lo que la dota de significado. De tal manera que si eliminamos estos referentes biográficos, contextuales o geográficos, la vida de la autora, sus experiencias vitales, o la situación por la que pasa, así como los gestos, los espacios y las tradiciones en que ésta es recreada el hilo conductor se corta, el diálogo y la comprensión se rompen. Me refiero a los diferentes modos de leer, más superfluamente o más en profundidad, transmitiendo ideológicamente las diferencias culturales, sexuales, o sociales.

Ligado a ello, otro de los aspectos importantes al respecto es lo que puede denominarse el ambiente que recrea y acompaña a la lectura, así como el sentido asignado por la escritora y cada lectora. De aquí, como aporta Varela (2003-2004) “hacer una historia de la lectura es muy diferente de hacer una historia de lo que es leído". En este sentido, es interesante la reconstrucción a partir de un dar cuenta de cómo se traducen culturalmente las diferencias sociales. Por tanto, texto, escrito (impreso) y lectura están relacionados, cuyos elementos diferenciadores acotan el sentido y las formas de leer.

En la lectura nos ponemos en juego nosotras mismas, que nos ponemos en relación con la persona que escribe, con su mundo y con las interpretaciones que realiza de él. Este texto ha sido leído por Concha, entrando en juego todos los sentidos y emocionándose por verse reflejada en estas palabras que hablan de ella, que son suyas y nacen de ella, de la descripción e interpretación que hace de su propia vida.

Es una lectura que transmite la reivindicación a través de unas palabras generadas, desde una escritura construida en un proceso mediador entre dos mujeres diferentes, desde un "re-organizar" ideas y separar la paja del grano. Quedarnos con lo significativo ha sido el objetivo principal para que estas páginas transmitan algo de lo que para Concha ha significado su vida desde la existencia misma que ha tenido. Una vida que, como veremos, parece que fluye a retazos entre un estar consciente y un estar inconsciente, entre lo permanente y lo perecedero, lo estable y lo transitorio.

Esto en el fondo, el cómo fluya o emerja, y en cómo se desarrolle o evolucione este proceso, está en Concha. Un sujeto femenino en construcción. Se transmite a través de ella, se refleja en su llanto, en su sonrisa, en su mirada, en la ilusión que transmite con su cuerpo, su interés, la presión o fraude que emerge de su eco de voz.

La importancia de este texto, de un producto relativamente permanente en el tiempo (el material escrito) es, como dice Concha, "algo que ha hecho". Pues aunque siempre lo sienta, nunca ha valorado, descrito e interpretado su vida, y mucho menos puesto en relación con la de otra mujer que comparte muchas cosas con ella, en la medida que se sitúa en el simbólico femenino. En este sentido, es un proceso de trabajo que da cabida a la diferencia sexual.

Este proceso lo considero importante por la transmisión cultural que tiene lugar, así como por los modos en que se hace explícita y presenta la palabra de Concha. Mi papel es de mediadora; mediadora de un proceso que tengo la sensación que nunca acaba, que siempre está en construcción, abierto y emergente, y que se construye y reconstruye permanentemente desde la escritura y la lectura. Asimismo, un proceso que tampoco quiere terminar desde las necesidades de Concha de transformarse. Lo percibo como el recorrido por su propio ser y por esa andadura por un proceso de individualización y toma de conciencia femenina de quién se es y de cómo se interpreta y posiciona ante el mundo en el que vive.

Uno de los aspectos desde la diferencia femenina que tiene importancia para mi en este trabajo desde el sentimiento de soledad o creación mutua de la escritora y la oradora. Para mí es un proceso de transformación de ambas porque las dos mujeres, la diferencia de serlo, se ve identificada. Esto se transmite en la escritura, que adopta formas específicas. También en la oralidad porque cada lectora interpreta el significado del escrito de una forma determinada. Para ambos casos es importante que no olvidemos la personalidad y las experiencias vividas de una y de otra, los referentes previos de significación de aquello que escribe o de aquello que le lee, sus códigos contextuales, lengua, edad, trabajos que desarrolla, etc. Son todos datos que nos ayudan a tomar el sentido de la expresión de la lengua materna a través de la palabra femenina (Martín Gaite, 1996)

Otro de los aspectos claramente identificados en las palabras de Concha es la diferencia sexual que caracteriza a las mujeres. Me refiero a ello desde la creación de un mundo en que tiene cabida el género femenino y masculino desde el respeto, la comprensión y el entendimiento mutuo del amor. Es la importancia de la diferencia sexual en el proceso de escribir y en el acto de contar. Es esa ayuda que refleja la profesora Wilson (2003-2004) que las madres realizan en su proceso de enseñanza y en su orientación para nombrar el mundo, dar nombre a las cosas y establecer relaciones y sentimientos. Todo ello desde el acto de nombrar, desde el pensamiento e intención de aquello que queremos nombrar y de la forma en que se quiere hacerlo.

Pero, sobre todo, esta diferencia es expuesta en el tema desde la diferencia femenina del ser mujer, desde el crear diferente, el pensar diferente, el sentir diferente... desde un vivir diferente las normas impuestas, la libertad femenina... Un ejemplo claro son las relaciones sexuales desde la libertad de establecer relaciones heterosexuales $\mathrm{u}$ homosexuales, siempre desde la diferencia de ser y existir libremente como mujer 
en el mundo, y de posicionarse en él desde los propios referentes femeninos, que no tienen por qué ser iguales a los de la otra, pero sí semejantes en la medida que ambos se sitúan o parten de un mismo lugar, de un origen semejante, el materno.

También es importante para mí a través de este tema cómo Concha se va nombrando se va definiendo poco a poco, a medida que se va encontrando, y cómo las decisiones que toma van cambiando en función de ello. El interior representa a una presa, exiliada o desterrada que, de pronto, tiene libertad por un momento para dar salida a su deseo femenino. Así se siente Concha y así la vivo en el proceso. Es como un caminar al lado de alguien que se construye en base a unos referentes previos, que la marcan y la definen, sin tener en cuenta lo que ella realmente pueda querer en la vida, pensar o sentir. Mucho menos, la posibilidad de autoría de su vida, que no es más que ser libre y vivir así la existencia.

Por ello en este proceso de entrevistas mantenido con ella, se nombra y se define como le gusta hacerlo, y tiene la total libertad para inventar su mundo, un mundo propio, por un momento, aunque sea unos espacios concretos y puntuales en el tiempo en que se desarrolla su vida. Sin embargo, para mí, es algo que se inicia, es como un nacimiento, como un parto... algo engendrado durante su vida previa, sus experiencias sacadas a la luz, un partir de sí, que se pone en juego conmigo, con lo que yo soy y con quien yo soy.

Pienso que estos deseos e ilusiones, también opresiones y reivindicaciones, que plantea Concha, son importantes en la medida que reflejan un pasado, un presente y la necesidad de cambio futuro. De igual manera, ello se ve reflejado en la lectora a través de la escritura, es como un eco, la sororidad. A partir de aquí Concha crea genealogía y sus palabras siempre serán recordadas. De aquí la importancia del escrito como papel y tinta física, permanente en el tiempo.

Para mí Concha es una maestra, que crea y transmite cultura, y de la que aprendo en este proceso. Sin embargo, ella tiene la sensación -y lo hace explícito- que aprende más de mí que yo de ella, que ella no tiene nada que aportar y que su palabra no tiene valor, pero no es cierto. Lo que ocurre es que no se reconoce autoridad porque parte de unos referentes patriarcales en los que su existencia ha sido construida y que son muy difíciles de desentrañar y desenmascarar.

Lo siento como un proceso de desmaquillaje, de desprendernos de esa máscara con la que nos situamos en el mundo, que ha sido elaborada para Concha, y para las demás mujeres, desde los mismos postulados patriarcales. Una máscara que estorba porque limita la visión, percepción e interpretación del mundo desde nuestro estar presente en él siendo y sintiendo como mujeres. El acto de quitar esta máscara frente a mí también es un proceso. Es como un tomar rodaje, confianza, empatía, seguridad de nuestras intenciones... un conocer-me, que -a su vez- me permite conocer-la.

Desde estas premisas, la protagonista transmite libremente sus preocupaciones, emociones, vivencias, impresiones, miedos y deseos... y desea mucho algo que tengo yo y que es significativo desde la transmisión oral: mi formación y mi tiempo propio, unido a los años que me distancian de ella. Se ve mayor a esta edad y siente imposibilidades para construir lo no construido antes. Esto refleja, por un lado, la importancia otorgada a la alfabetización, como vía o instrumento de liberación femenina y construcción de una libre identidad.

Por otro, la opresión patriarcal sentida desde el mito o ideal de eterna juventud. Una mujer que ya nos es válida a estos esquemas porque su hijo y su hija se hacen mayores y siente por ello un hueco, un vacío, en su vida. Siente por ello una ruptura, una desilusión, la necesidad de un tiempo dedicado, un tiempo vivido por y para los/ as demás y que ahora tiene que aprender a cubrir. Toda una reorganización existencial femenina de una vida organizada en torno a la familia.

Así define Concha su posición en ella, desde la utilidad que tiene para garantizar el cuidado de su vida, orientarles y beneficiarle; ¿Dónde queda Concha? ¿Qué hace Concha desde la inutilidad a la que un sistema patriarcal la ha abocado? Por ello que sus palabras se tambaleen entre el ser y el no ser, entre las posibilidades y los impedimentos, entre los sueños y las frustraciones de no alcanzarlos. En definitiva, lo que yo he definido, entre la libertad y el exilio, desde el miedo a la transmisión de su propio deseo -incluso a su propia pareja, con la que lleva conviviendo mucho tiempo y ha tenido dos hijos-.

Todo esto lleva consigo la importancia de la creación de sujeto femenino, de una identidad femenina desde las relaciones de autoridad, que se constituyen desde esta diferencia femenina de situarse en el mundo. Otro de los aspectos que apunta Concha es el valor que otorga a la educación de las mujeres, a su educación, ya sea en el ámbito de la educación formal o pública, o en el ámbito del propio del hogar. En este sentido, nos transmite una importante comparación con su hermana, más pequeña que ella, pero a la que le dieron más posibilidades en su juventud. Más tarde, los efectos de entrar en el mundo heterosexual la llevarían a casarse con el hombre, que su padre consideró "su futuro" "su destino".

La diferencia formativa de Concha con su hermana la llevan a un proceso de aprendizaje de ésta a la primera; no sólo en cuanto a la escritura, sino también en cuanto a la búsqueda de empleo y a las aspiraciones profesionales. Esta práctica de enseñar y enseñar a escribir significa, en mi opinión, una toma de conciencia desde la 
búsqueda de su yo en la sociedad patriarcal de este tiempo. Son importantes aquí las relaciones de autoridad entre las mujeres -hermanas-

La alfabetización significa la liberación femenina y la posibilidad de una existencia libre, aunque en muchos casos signifique libertad de mente y reclusión en la casa familiar, de la casa paterna y más tarde en la jaula patriarcal donde serán cortadas, en su totalidad, las alas a Concha. Parece que ya no hay regreso, no hay salida. Este encerramiento o este espacio de represión lo expresa Concha como un periodo negativo en su vida y como un periodo en conflicto consigo misma. Éste se caracteriza por lucha entre la represión histórica-cultural-patriarcal del momento en que vive y la necesidad interior de libertad como sujeto femenino.

Sin embargo, por otro lado, también lo siente útil. Esta utilidad le viene dada porque en este encerrarse en su propio hogar comienza a disponer de unos espacios y tiempos propios cuando los demás miembros de la familia están en sus ocupaciones. Ella es la única que no habita en los espacios públicos y que dispone del privado para organizarlo a su antojo, siempre y cuando desde la respuesta a sus ocupaciones como esposa, madre y ama de casa.

Es por disponer de estos tiempos cuando Concha comienza a disfrutar de la relación con otras mujeres; su hermana y su madre, en primer lugar, pero también con otras mujeres debido a ocupaciones familiares, como por ejemplo la Asociación de Padres de Alumnos/as, que se convierte en una asociación de mujeres, las madres de los alumnos y las alumnas. Es aquí donde comienza la creación del sujeto de Concha y ocurre otro punto de inflexión importante en su vida. Comienzan periodos, etapas y tareas de reivindicación por derechos y espacios propios que piden y reclaman a través de sus hijos e hijas.

Se va desarrollando en ellas todo un proceso de refuerzo, de aumento de autoestima y de concienciación de su estar en el mundo, de lo que pueden hacer y no les dejan, no les permiten realizarlo. Estos espacios, que comienzan a multiplicarse con miles de motivos, comienzan a utilizarse como excusas. Se fomenta a través de ellos la capacidad de reflexión creativa desde las relaciones de mediación femenina, que son relaciones basadas en el entendimiento del amor.

Ésta es otra idea que se desprende de estas reflexiones iniciales, y cuyo ejemplo más claro se ve desde las relaciones lésbicas entre mujeres. Ellas llevan a la búsqueda de sí desde el encuentro con la otra, representando el exilio del cuerpo femenino y la negación doble, como mujer y lesbiana, a la que el patriarcado las somete. Es un tema donde se resalta el interior, la persona en sí, y no las posesiones o el ambiente material que las rodea. Tiende hacia la espiritualidad, hacia la creación del sujeto femenino, hacia la identidad libre desde la práctica de la diferencia. Se resalta el valor de la escritura y la lectura como medio de hacer visible la grandeza femenina, así como las creaciones o generaciones, la autoría de sus producciones, ya sean literarias o artísticas. Se resalta un origen femenino como base de la construcción del mundo.

Un origen en el que tienen cabida mujeres y hombres desde el amor femenino, el amor materno, y todo ello es expresado a través de la escritura, de la palabra, del lenguaje femenino, y se vehicula a través del interlocutor o interlocutora desde el entendimiento de este amor y las interpretaciones particulares que cada cual realiza desde la diferencia de ser mujer -u hombre- y de estar en el mundo. Christine de Pizan, en su obra la ciudad de las damas, refleja precisamente la diferencia desde el entendimiento del amor. La posibilidad de un mundo donde se tenga en cuenta al otro y a la otra, desde la posibilidad de ser dos, que es femenina.

De ello la presentación de modelos diferentes, de formas de vida distintas, más válidas para ellas en la medida que las crean desde la libertad de su ser mujer y situarse en el mundo. Un ejemplo, son la cantidad de saberes y de prácticas mágicas que las mujeres han desarrollado a través del tiempo (Caballero, 2003-2004). Éstas han sido importantes en la medida que les han sido útiles como formas de vida y han creído en ella, es decir, en la medida en que les han reconocido autoridad.

También la presentación en este tema de modelos diferentes al modelo matrimonial, la creación de relaciones sexuales alejadas de una heterosexualidad obligada y presentada como única alternativa. El hecho de que se convierte en un continuo, aludimos aquí a la sororidad femenina, y que se vea representada la palabra en la otra y, a su vez, se transmita, hace que se convierta en una transmisión ideológica, cultural y específicamente femenina. De aquí que las mujeres se representen como creadoras de cultura escrita. Ello, precisamente, es lo que hace Concha a través de mí.

\section{CARACTERÍSTICAS DE LA INVESTIGACIÓN}

El trabajo se centra en el análisis del proceso oral construido entre la relación de Concha conmigo. La una como protagonista y la otra como investigadora que se pone en relación con la primera, y cuyos pensamientos, interpretaciones y visiones del mundo son intrincados y unidos como si de una madeja de hilo se tratara. En este proceso de hilar, cada vez más fino, en la medida que vamos obteniendo un mayor significado y más profundo de las palabras, como si sílaba a sílaba construyéramos todo un libro. Ese ha sido el proceso vivido y sentido por mi parte en este trabajo. En cada contacto un avance, una evolución, pero también un retroceso, para volver a avanzar. Es construir poco a poco desde el deconstruir y desmontar lo que en un principio parece evidente. 
Para trabajar con Concha y llevar a cabo un proceso de mediacion, de apertura desde la diferencia, la técnica que, en mi opinión, es más rica y que he seleccionado por ello se encuadra bajo el método biográfico. Pienso que éstas son especialmente idóneas para la investigación de procesos de cambio o transformación social. "Es de hecho la investigación basada en las historias personales, como su mismo nombre indica, la que puede obtener el debido enfoque del cambio histórico, como no es posible hacerlo con otros métodos" (González y San Miguel, 2002). En este sentido, he recurrido a la reconstrucción de su historia a través de este método biográfico.

Cómo afronto yo la investigación sería otra cuestión interesante y que pienso debe quedar expresada: poniéndome en primera persona y a través de un proceso de investigación participativa en la que establezco una relación con el sujeto investigado. A través de ella, ambas estamos sujetas al cambio. Hacer realidad el deseo de llevar a cabo esta investigación centrada en el análisis de la vida y la existencia de Concha ha significado como poner un espejo frente a mí y verme reflejada en otras semejantes, en ella. Y no es precisamente porque, a simple vista, seamos idénticas, todo lo contrario.

Sin embargo, a veces juzgamos por apariencias, sin rascar en lo más profundo porque se pone en juego la verdad (Muraro, 2002-2003). Una verdad que es femenina y que duele, en el sentido que rompe con el montaje que ha sufrido el escenario de su vida y tiende a modelarlo, a su imagen y conforme a su deseo. Tiende a ser sustituido por otro más válido para ella, pero que no lo es para otros y tampoco es aceptado. Pienso que cuando actuamos en la vida y tomamos una decisión no lo hacemos en base a nada, mucho menos las mujeres. Nuestra acción tiene un sentido, un significado, un por qué, al igual que este trabajo para mí. De ello sólo puedo contar aún el inicio, porque el final está sin definir y tendré que llegar a las últimas líneas y volver al principio (puede que en más de una ocasión), todo ello con la intención de comprenderlo.

Con esta investigación hay un compromiso personal, una búsqueda del por qué me identifico con Concha en relación a su existencia, a pesar de mis diferencias con ellas en cuanto a la situación que vivo. Por qué a partir del contacto con Concha, por mi propia elección y deseo, estoy en estado de alerta y a partir de entonces comienza mi preocupación por conocerla más, comprenderla, y compartir sus vivencias a partir de su trabajo y el mío, de su vida y la mía, de cómo ha tomado y toma las decisiones que afectan a su vida y de cómo las tomo yo. Ello pienso que es un buen referente, una muy buena medida femenina de y para la existencia y la identidad femenina en las que, en fin último, me centro en este trabajo.

A partir de las cuestiones que planteo puede deducirse cuál es el sentido de la investigación realizada. Ésta recoge para su análisis aporte del pensamiento y práctica de la diferencia sexual trabajados durante el presente curso académico en el primer y segundo módulo de formación del Máster en Estudios de la Diferencia Sexual impartido desde Duoda. Intento con ello analizar a través de la vida de Concha la importancia de la transmisión ideológica para la identidad femenina. Esta transmisión es relevante analizarla desde la oralidad, la escritura y la lectura, porque son instrumentos todos que manifiestan y hacen explícito un lenguaje. Pero un lenguaje que no se asemeja y no casa con los códigos patriarcales imperantes, más bien lo critican duramente, haciendo visible opresiones y reflejando nuevas formas posibles de sentir, ser y posicionarse como mujer -también como hombre- en el mundo

Se trata, por tanto, con este trabajo de dar la palabra a Concha, e intentar reflejar a partir de este escrito, lo central de nuestra relación. Por lo menos lo que han sido los puntos de inflexión básicos en su vida y los motivos de los mismos, así como nuestros significados propios en relación al proceso. En este sentido, es importante que se escuche a Concha, su voz, respetar sus códigos de decibilidad, para hacernos poner en palabras su existencia, sus vivencias, experiencias, deseos, ilusiones... ello significa reconocerle autoridad y hacer que se transforme en la propia investigación reconociéndose a sí misma como actriz a la vez que espectadora de un espacio y un tiempo que les han sido dados, que les son propios.

En definitiva, partir de su propia experiencia narrada, la cual se pone en relación con la mía, con lo que yo he vivido. Todo ello se construye desde la diferencia de generaciones a las que ambas pertenecemos y la diferencia de una biografía y un contexto que marcan. Es importante esta experiencia compartida en la medida en que otras muchas mujeres pueden verse reflejadas en este escrito en un tiempo y un espacio reconstruido y que se para en estos momentos. Son bajo estas coordenadas espacio-temporales donde lo construido se desvanece para llegar a re-construirse y transformarse.

En este trabajo se lleva a cabo, por tanto, una historia de vida de caso único. Es una biografía individual siendo el sujeto, una mujer, la que nos narra sus experiencias y vivencias, al mismo tiempo que la analiza y la interpreta. La investigadora intenta, a través de la mediación y de su implicación, dar pistas para este análisis que no es más que referencias desde sus propios referentes, formación, vivencias y códigos. En este sentido, es individual, porque la mujer seleccionada es la que nos habla de sí misma desde los propios referentes socioculturales en los que se ha desarrollado y vive.

También porque su discurso depende de sus propias características personales y psicológicas -y de las mías propias. Sin embargo, entendemos que, en muchos sentidos, la biografía es social. La cultura opera como mediadora en la elaboración de la experiencia, pero ésta es compartida. Ejemplo de ello es el significado de la escritura para las mujeres, o de la oralidad, en definitiva de la palabra femenina. 
Muchas escritoras en sus trabajos parecen que nos cuentan de nosotras mismas. Esto es así en la medida que se sitúan en otro orden, desde otro lugar, desde el simbólico femenino. Este origen es compartido en las mujeres y por eso me refiero a la biografía, entendida como medio de expresión de la experiencia femenina y a la escritura o a la oralidad como instrumento para ello, como algo social. En este sentido, la biografía es social porque es compartida, comparte referentes femeninos, porque hablamos desde el orden simbólico de la madre.

Pensar desde la propia experiencia es importante en la medida en que ésta dimensión vital es transmitida en la escritura o a través de la palabra oral. Ello adquiere diferencia, diferencia que es femenina, pero cuya raíz es común: el orden simbólico de la madre. Dentro de este contexto, los referentes histórico-temporales son importantes, pues las coordenadas vitales y existenciales tienen significado diverso -desde la diferencia sexual que lo caracteriza- para unas mujeres y para otras (también para unos hombres $\mathrm{y}$ otros, $\mathrm{y}$ entre estos y aquellas). $\mathrm{Y}$ es que en todo ello tiene mucha influencia el momento histórico-cultural, social y político que se vive, así como las situaciones particulares sentidas, que no tienen por haber sido expresadas, quizá porque no se haya encontrado al interlocutor o interlocutora acertada.

Muchas veces se sigue negando la palabra a las mujeres y no dando valor a la persona, a su interior. La palabra es coartada en la medida que no es escuchada, que no se deja fluir. En este sentido, la mujer que participa en esta investigación transmite una necesidad. Necesidad de relacionarse con otras mujeres a las que transmitir sus deseos, sus inquietudes, sus necesidades. Todo ello lo defino como una relación de autoridad. En ella se dejan de lado las características personales entre investigadora e investigada y las diferencias entre ellas, porque desde el comienzo de la investigación, desde que comienza a gestarse se establecen códigos comunes que rozan lo simbólico. Estos códigos favorecen la comprensión y el conocimientos de ambas en la medida que se sitúan en el origen y éste es compartido.
La historia individual construida desde la experiencia femenina y entendida bajo esta subjetividad única es la base para la construcción de lo social. Necesidad de transformación que tiene lugar en cada mujer y que se contagia en nosotras como grupo. La construcción de la biografía, un trabajo que se establezca desde la mediación, necesita de un ponerse en juego en primera persona, pues como pone de manifiesto Alonso (1998), "la memoria aparece así no como una simple descripción de acontecimientos parados, sino como la apropiación individual de una cultura histórica que siempre tiene que ser mirada desde lo colectivo".

Esta historia de vida se construye a través de tres entrevistas en profundidad. Las entrevistas que se llevan a cabo permiten explorar las condiciones de existencia y de vida, los referentes personales, culturales, familiares, las opresiones, los deseos, las necesidades, las inquietudes, las formas de vida... De ellas se produce un material en forma de texto, escrito, a través del cual se refleja la palabra de la protagonista en interacción con la investigadora. Este material necesita de interpretación para lo que es fundamental la intuición. Para mí, el fenómeno discursivo adquiere sentido desde una producción simbólica.

Por este motivo, el análisis del material que realizamos se hace desde una doble perspectiva. Ello significa tener en cuenta el nivel sociocultural y el nivel sociosimbólico En el primero de ellos hacemos referencia a los modos de vida que desarrollan las mujeres. En el segundo, se pone el acento en las actitudes, las representaciones y los valores individuales (Bertraux, 1976). Esto implica tener en cuenta la experiencia femenina y la propia descripción de ella, así como las formas en que ésta es interpretada desde el propio sujeto, en este caso, una mujer. Son elaboraciones personales mediadas por la cultura (por su peso patriarcal) y por la historia desde las apreciaciones o interpretaciones narradas por Concha.

Los análisis realizados nos ponen en evidencia la transición del periodo franquista a la socialdemocracia que vive y cómo le ha repercutido en sus pensamientos y

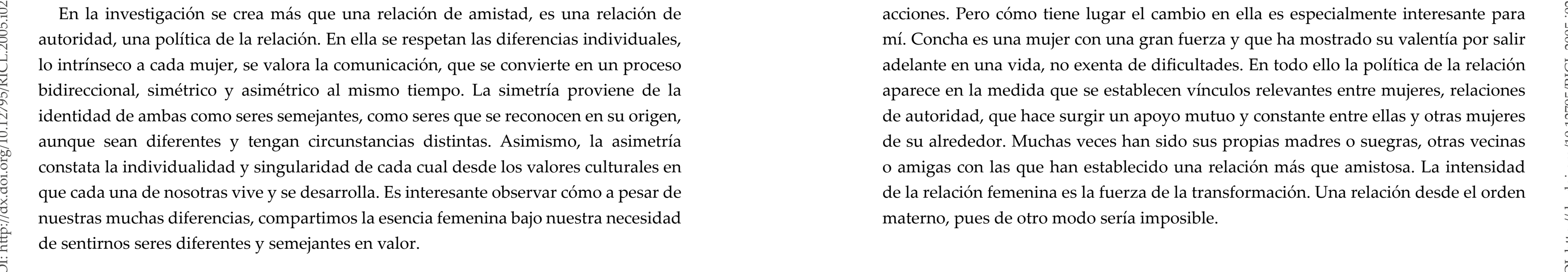

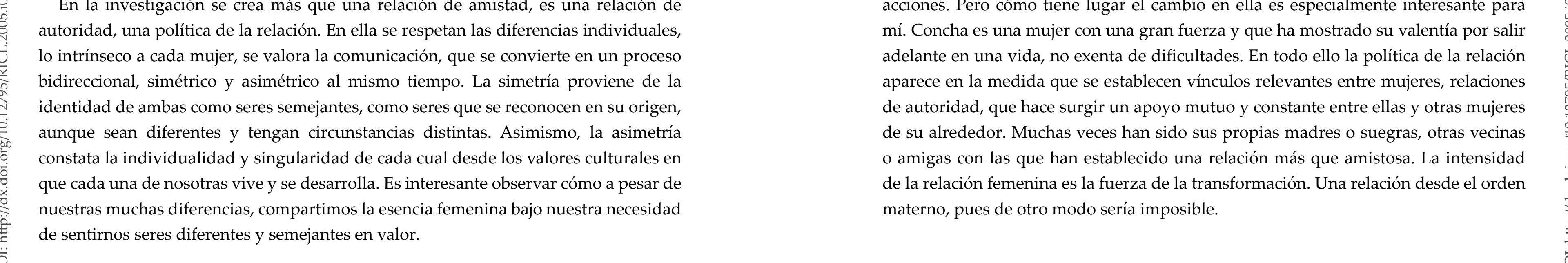

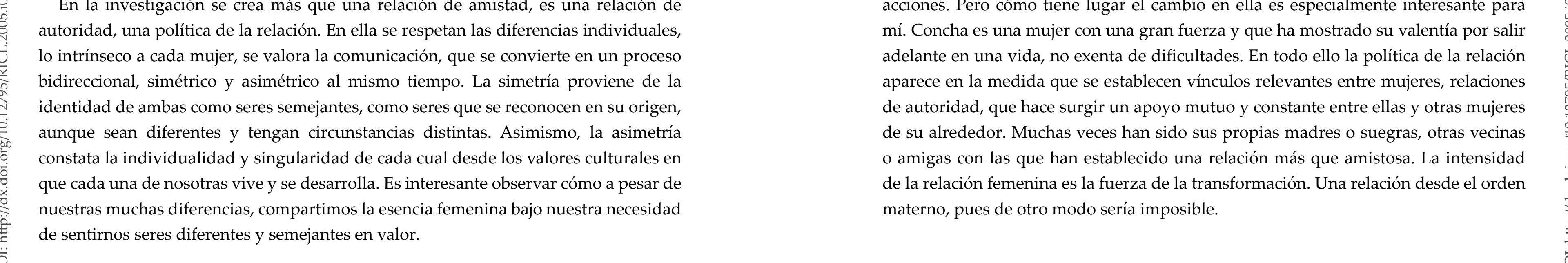

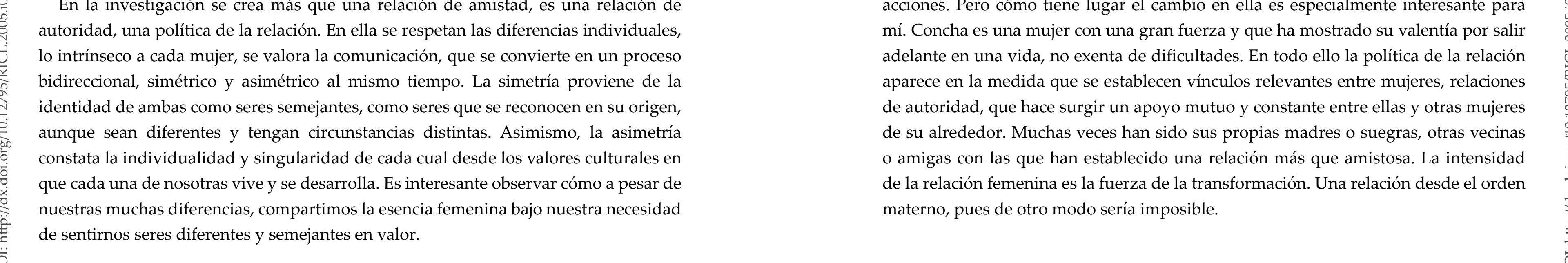

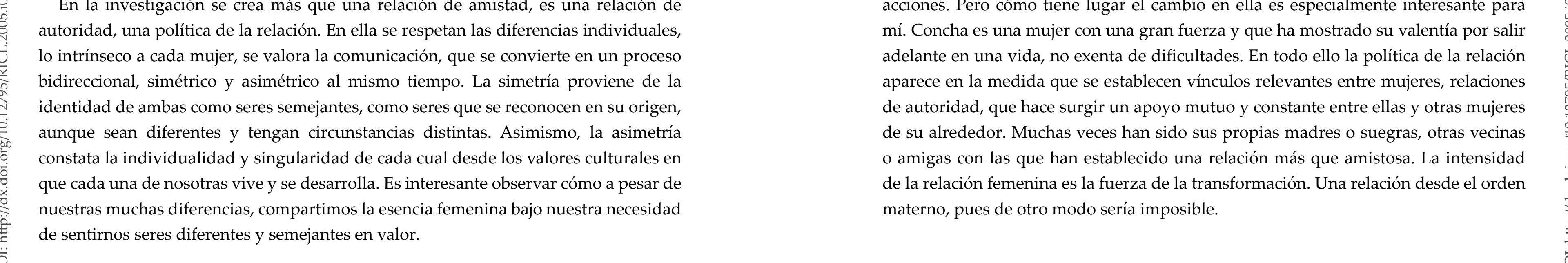

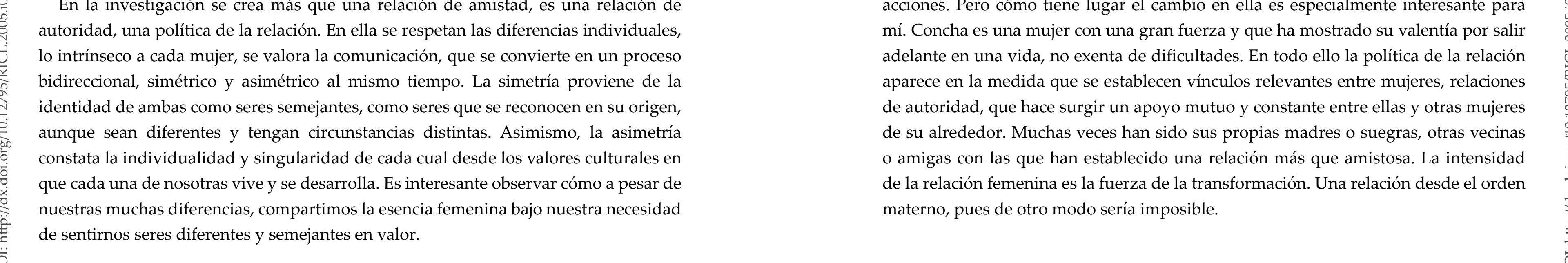

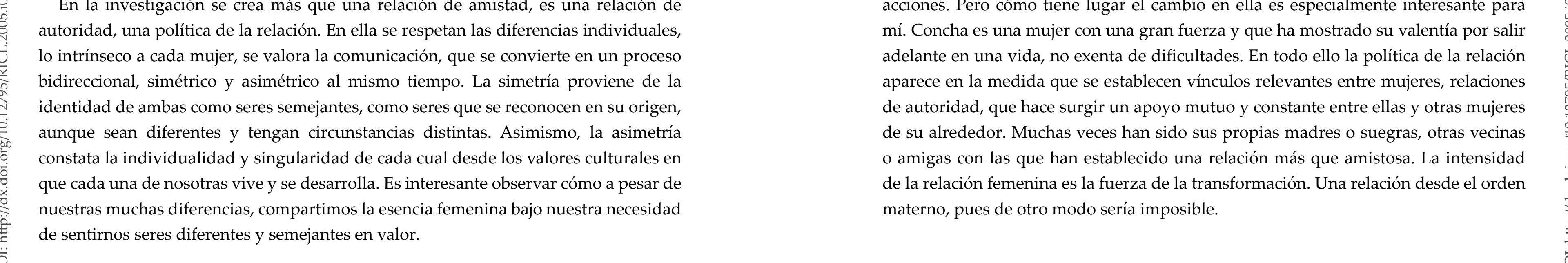

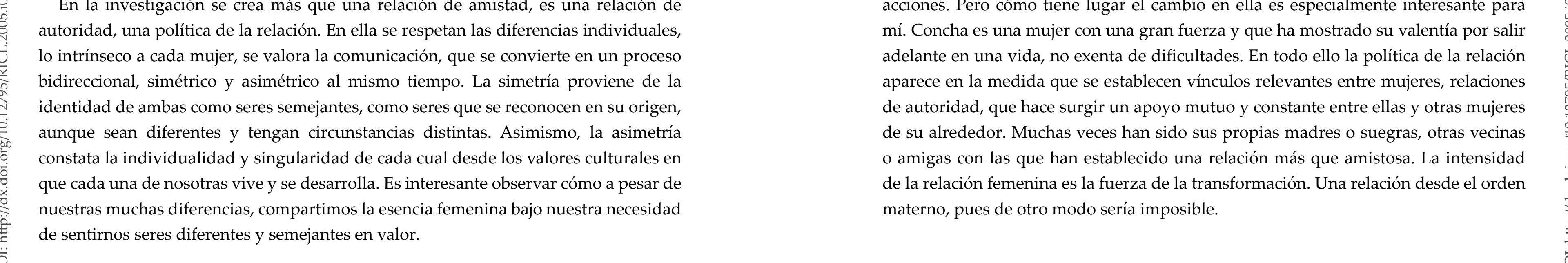

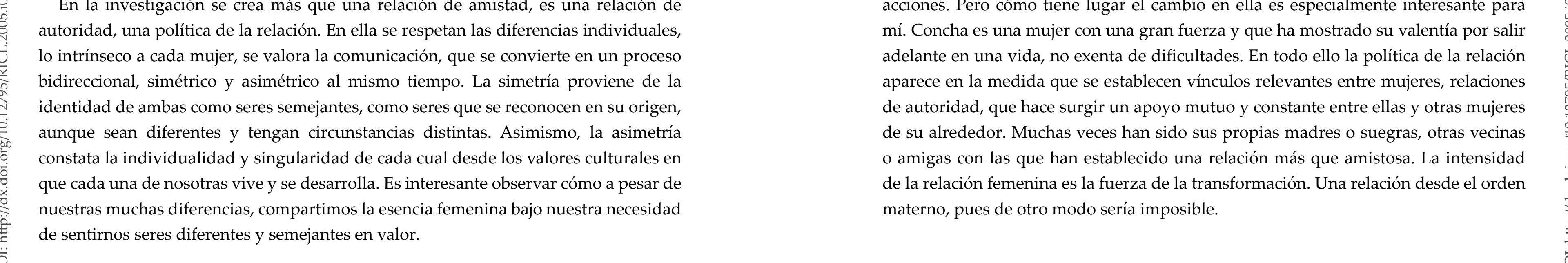

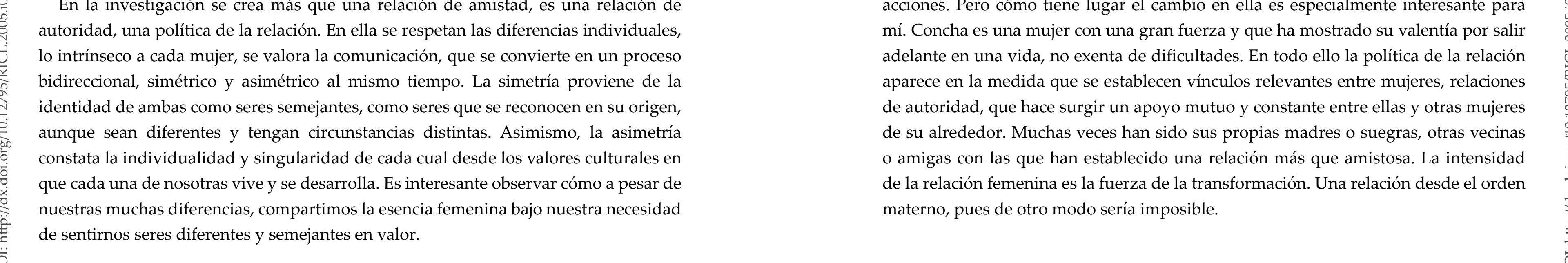

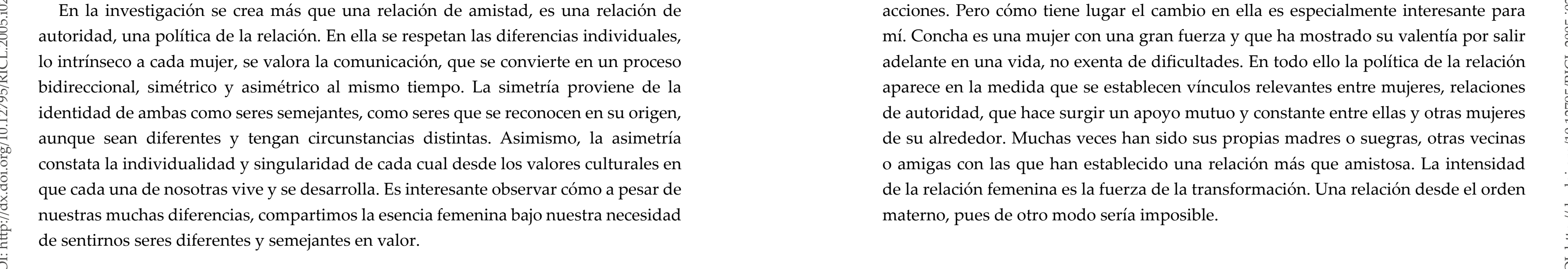

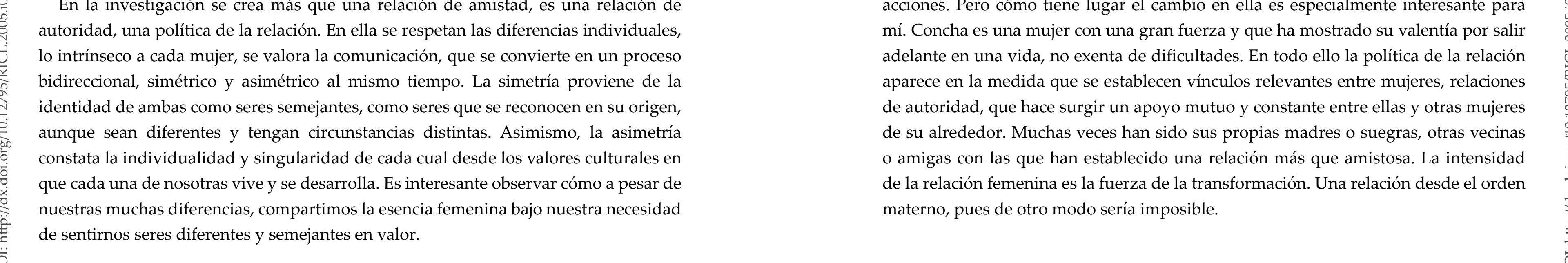

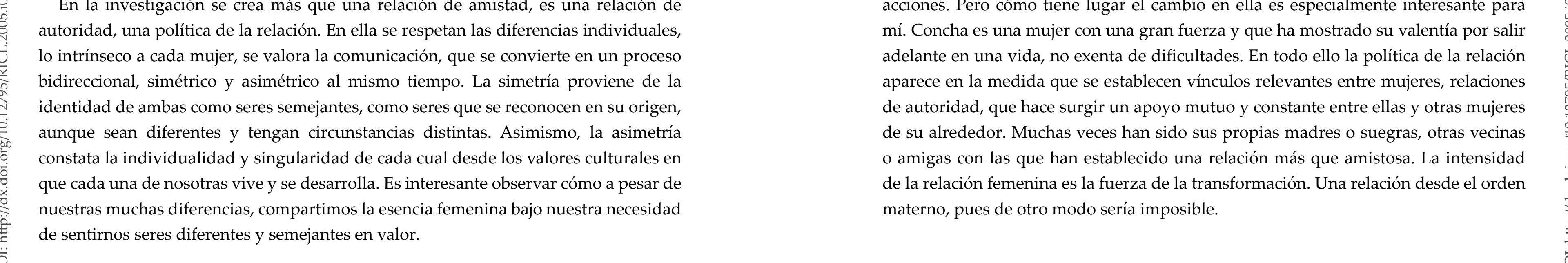

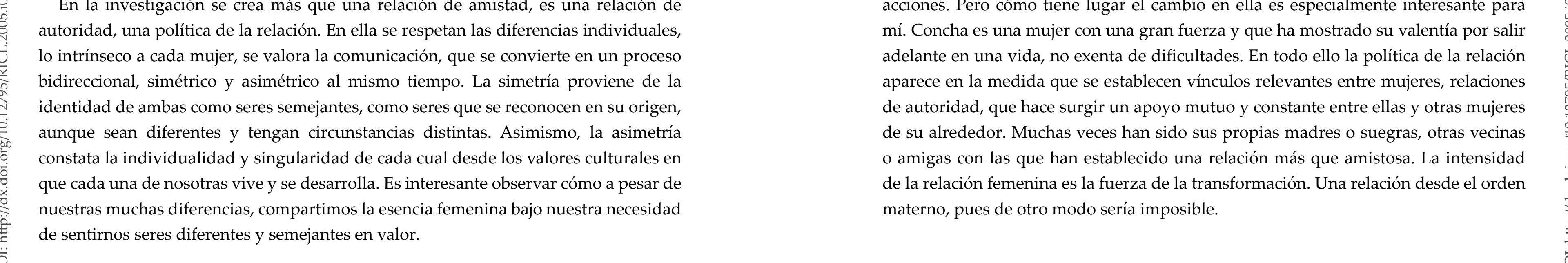

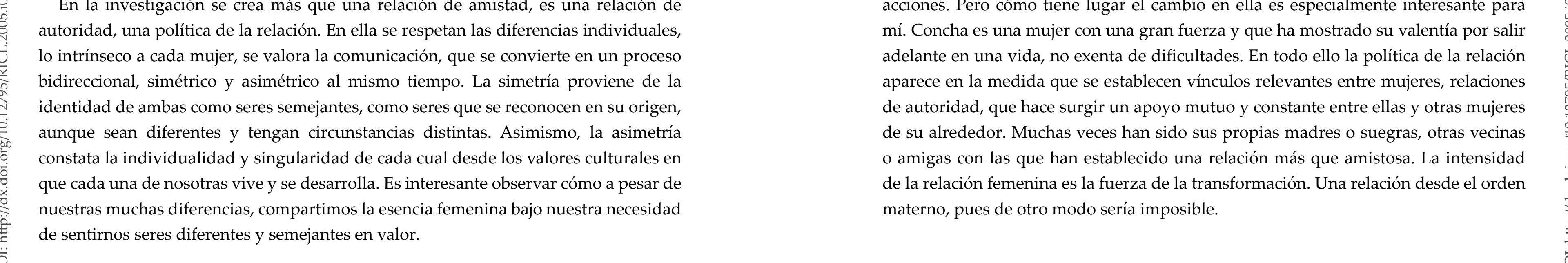

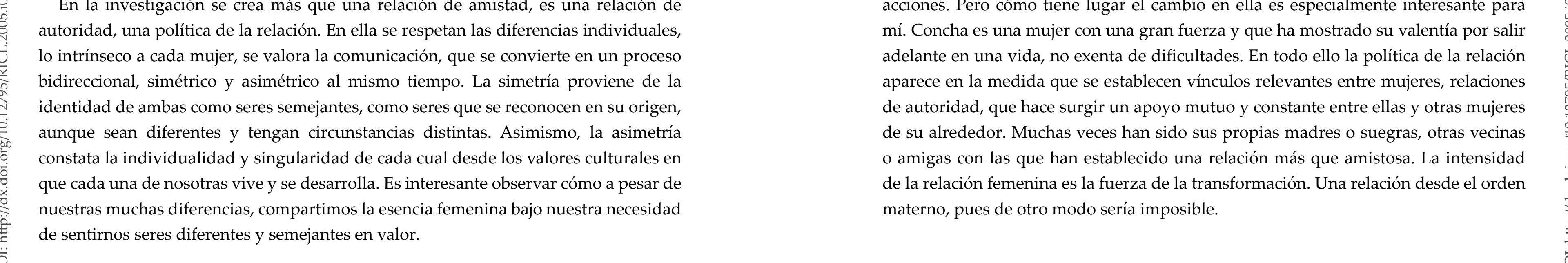

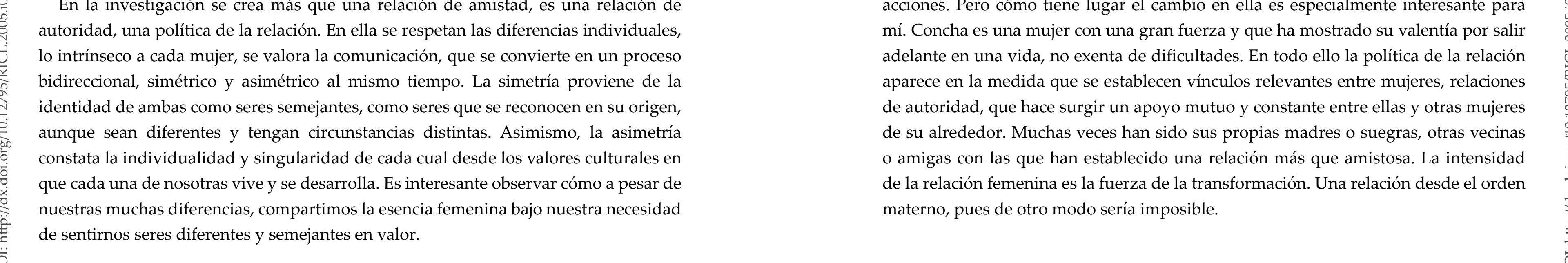

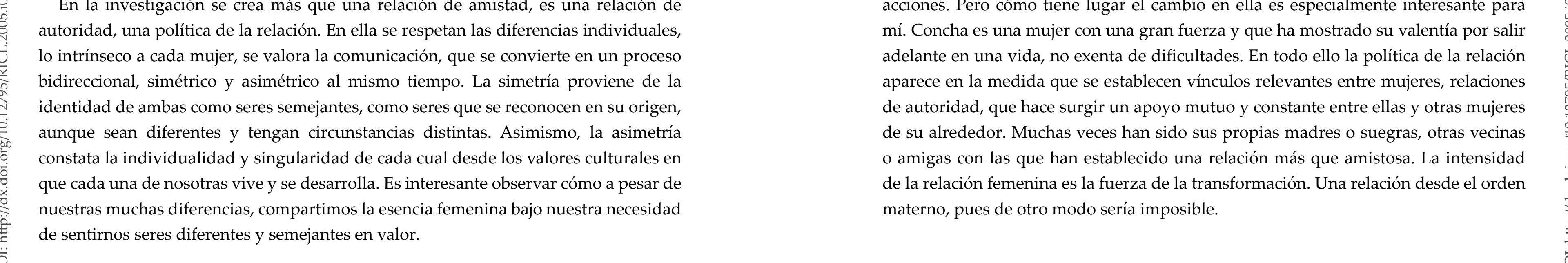

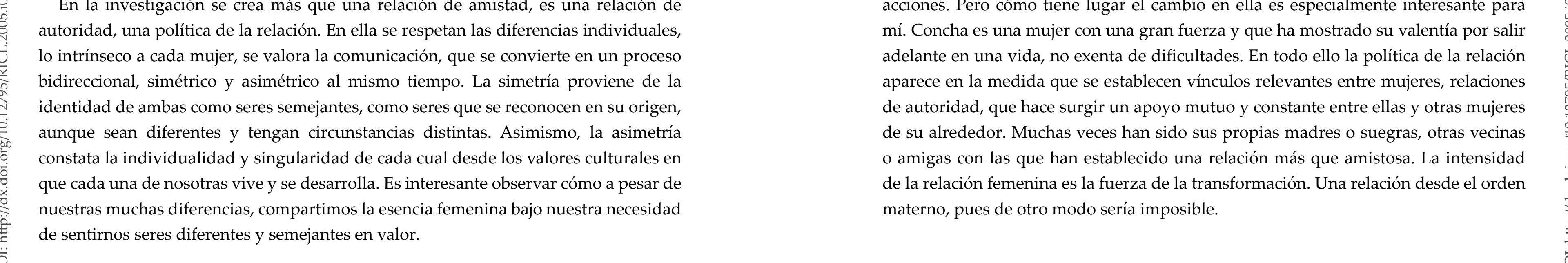




\section{LA VIDA DE CONCHA: EXISTENCIA E IDENTIDAD FEMENINA}

Concha es una mujer de pueblo, que vive en una zona rural de la provincia de Sevilla. Tiene cuarenta y cinco años, es madre, ama de casa, trabaja largas jornadas fuera de la casa, es muy inquieta y, como ella dice, se define porque le gusta siempre ser ella, aunque eso le cree más de un problema. Para mí, la existencia de Concha y su paso por el mundo tiene un importante valor para la creación de genealogía femenina. Muy lejos de ello, los modelos que crea y las estrategias de vida que desarrolla son desconocidas para nosotras, pues no es una mujer relevante socialmente. En esta línea, Concha manifiesta el rechazo, el sentimiento de un medio social que la aísla, la excluye y la aparta. Ello tiene sentido desde el exilio femenino y las diferentes miradas de situarse en él o sentirse exiliada.

Su palabra necesita ser oída y mi intención en este trabajo es sacar a la luz su vida, sus experiencias, su existencia y su creación como mujer, así como analizarla desde la relación que hemos creado desde el principio de este trabajo. Esto es algo que también resalto, por el significado que para ambas ha tenido. Nos hemos visto confrontada la una en la otra, desde nuestras similitudes y, a pesar, de nuestras tantas diferencias. Antes de pasar al análisis más en profundidad de lo que ha sido su vida, y del ejemplo transmitido mediante su palabra, paso a reflejar los grandes hitos señalados por Concha desde su nacimiento. En ellos me centraré desde una doble perspectiva; en primer lugar, teniendo en cuenta el análisis de la propia protagonista y del entorno en que vive. En segundo, analizando el lenguaje y los elementos de tipo simbólico que nos pone de relieve en sus entrevistas en profundidad y en mi contacto con ella.

\section{INCIDENTES CRÍTICOS}

- Nacimiento, año 1959.

- Infancia: su familia.

- Comunión: comienzan las diferencias y malestares en Concha.

- Su trabajo dentro y fuera de la casa: el cuidado de su familia, la ayuda a su madre (trabajo de su madre), la costura, la mercería y el envasado de aceituna.

- El peso de la tradición, Iglesia y convicciones maternas.

- La lucha de Concha: su entrada en el Centro Juvenil.

- Abandono de la escolaridad (el eterno deseo por formarse y tener trabajo que le guste).

- Primer embarazo (críticas, agresiones... exilio de la localidad, de su familia, de su cuerpo... Un chico.
- Un hogar propio (urgencia en la construcción): el encerramiento, anulación de su identidad y posibilidad de libertad femenina. Las confusiones y conflictos consigo misma.

- Abandono de su único trabajo remunerado, fuera de su hogar, y de las únicas posibilidades de un futuro libre. La vergüenza de Concha, el peso de la cultura patriarcal y lo religioso, la gente del pueblo.

- Casamiento: la entrega de Concha, control masculino, exilio de su cuerpo y de su identidad

- Nacimiento de su primer hijo: la transgresión de la norma, un ejemplo de lo no permitido en una mujer.

- La vida en el hogar "propio", su marido y su embarazo: el significado de todo es diferente para ambos, la acción se pone en juego a través del pensamiento y deseos distintos.

- Traslado a Andujar por motivos laborales de su marido: el significado de la marcha (posibilidades, formación, relación con mujeres, libertad, autonomía... es donde forja su identidad lejos de las opresiones de la casa paterna y limitaciones, la lejanía de la familia, la soledad).

- Regresa a la localidad en que nace y accede a una Asociación de Mujeres (libertad unos espacios y tiempos propios) posibilidades de formación, de salir, de tomar decisiones...

- La entrada en la Asociación de Padres de Alumnos y Alumnas: creación de redes de mujeres, autoridad y libertad.

- Segundo embarazo. Una chica. Maternidad completamente diferente. En ella proyecta proyecciones, deseos, malestares pasados...

- El compromiso de Concha para con su hijo y su hija, un compromiso para con su entorno y con ella misma. Las relaciones de Concha con sus hijo e hija.

- La guerra con su madre: la paz aumenta a la muerte de su padre. Concha reproduce sus roles, responde al patriarcado desde la búsqueda de estrategias que le permitan una identidad más coherente con su ser y sentirse mujer en el mundo. Las relaciones de Concha con su madre.

- El valor de las relaciones generaciones para la transmisión ideológica y cultural.

- Una actualidad entre la guerra y la paz: su matrimonio, sus hijos y ella misma (su ser mujer y situarse en el mundo, no es más que la búsqueda de sí misma y la necesidad de un vivir libremente desde su propio deseo de ser mujer). 
Concha nace en un pueblo rural en una familia de clase media-baja y en una época social cuya coyuntura política pasa por un régimen dictatorial. Es un entorno de pobreza y de privación social, política, económica y, cómo no, sexual. Tanto su padre como su madre trabajan. El primero lo hace en el ámbito de la agricultura. La madre de Concha, además de cuidar a su hermana y sus dos hermanos, se dedica a coser en un pequeño taller que tiene en su propia casa. El sentido del trabajo de su madre es debido a las escasas oportunidades económicas que tienen y a la necesidad de mantener a una familia amplia.

La madre de Concha es conocida en el pueblo por sus labores como costurera trabajo que realiza porque le ha gustado siempre la relación con la gente, con las otras mujeres. También hace bordados y otros trabajos manuales relacionados con el tejer. Estos trabajos, que realiza en un pequeño taller que monta en su propia casa, significan para su madre la oportunidad para alejarse de las estructuras patriarcales que le vienen impuestas, del dominio y del control de un hombre, así como de búsqueda de reconocimiento de autoridad, tanto en su familia como por la gente de su pueblo, desde los saberes y conocimientos que desarrolla.

Concha, desde su más tierna infancia, ha de ayudar en casa, por ser la hermana mayor. En realidad el mayor es su hermano, pero es la niña mayor y la que tiene una personalidad más fuerte, según le dice su madre. En ella recae desde pequeña todo el peso del hogar que debía recaer en su madre, además de otras labores de apoyo a la costura, como el hilvanar, pasar señales, o coser botones. Todas tareas mecánicas en las que Concha se va instruyendo con la ayuda de su madre.

Es importante, en este sentido, el peso de la transmisión ideológica, la enseñanza transmitida de madres a hijas, así como los estilos de vida, modelos femeninos que se reproducen. Todo ello se refleja mediante la oralidad, que adopta importancia también desde el trabajo que Concha y su madre realizan relacionado con el hilar y el tejer. Para mí es la puesta en juego de la palabra, de sí mismas con la sociedad y en entorno que les toca vivir; todo un ejemplo de autoridad femenina. De ahí que tenga la costura como una vocación y que siempre lo encuentre como salida formativa u ocupacional, porque es algo que sabe hacer y para lo que no necesita contar con un título formativo. Pero de la formación hablaremos más adelante.

El trabajo para Concha es duro, "no alcanzaba al fregadero ni a la cocina y recuerdo cuando mi madre me enseñó a hacer los tomates". Faenas, como ella las llama, que tenía que realizar antes de irse a la escuela. Es la que se encarga de la casa, de su padre, de su hermano y es el apoyo de su hermana. Es como si quisiera mantenerla en un anonimato con respecto a lo que ella sabe y siente del mundo a tan corta edad. Es la defensa y la ayuda a otra mujer, al igual que la madre, que ayuda hoy a la hija para que se forme y se haga un hueco en la sociedad que continuamente la rechaza por su sexo.

A Concha le toca vivir en un duro tiempo de represión. Más cuando vive en un pueblo rural, muy pequeño, que está muy ligado a la tradición cristiana. Su madre va a misa todos los días y pretende reproducir estas convicciones en Concha, aunque en sus palabras siempre resalta con fuerza su resistencia; la resistencia a la incoherencia de la vida y a hacer cosas que no siente o no cree. Luchar contra todo ese mundo contra el orden patriarcal, crea en Concha desde la más tierna infancia un desorden simbólico que la sumerge en el conflicto, en la incoherencia del mundo. Pero Concha podrá seguir viviendo un tiempo más reproduciendo lo que ha visto en su casa y gozando de cierta libertad. Me refiero a la libertad por ser pequeña, a la libertad por ser una niña.

Como reflejaré, la entrada en el mundo heterosexual significa para ella nuevas opresiones desde el deseo de vivir una vida más libre. Sufre el engaño de la sociedad patriarcal en que vive, que la lleva a equívocos. En ello se ve la importancia de transmisión ideológica, que cobra sentido desde la transmisión generacional. Concha reproduce con ello los valores de su entorno, aunque transgrede la norma. Eso, precisamente, es lo que sufre.

Sin embargo, Concha, en cierta medida, reivindica su libertad con su acción, haciendo presente su disconformidad, criticando en la medida que puede las discriminaciones que siente por no tener cabida como mujer en un mundo hecho por y para hombres. Lo que Concha nos transmite con ello es un mundo, una sociedad patriarcal, en la que no tiene cabida la diferencia sexual.

LA NECESIDAD DE RUPTURA ANTE LAS OPRESIONES SENTIDAS: EXILIO FEMENINO

Desde las opresiones que Concha siente es necesario la ruptura. Concha se siente fuera de ese mundo, pero al mismo tiempo presa de él. Quizá parezca contradictorio pero es lo que transmite a lo largo de las entrevistas. Se siente fuera del mundo en la medida que no es el mundo que ella quiere, que ella siente, que ella piensa. Ella tiene otro imaginario, diferente al masculino, otro deseo, otra imaginación. La protagonista necesita un mundo pintado por ella en el que abajo ponga su firma, al igual que el pintor hace en su cuadro.

Con ello no reivindico la popularidad de Concha, pues lo que ella quiere no es precisamente esto. Concha necesita crear-se libremente, constituir-se, llegar a ser mujer libre en el mundo, para lo que se necesita reconocer-se y reconocer-nos autoridad. Me refiero a algo muy sencillo, como es la autoría de su vida, su propia identidad y el permitir y dejar ser a Concha. 
Esta necesidad -opresión sentida- que plantea Concha se manifiesta a través de su relación con otras mujeres. Es un deseo sentido, manifestado y explícito al que se da salida desde las propias estrategias desarrolladas por Concha en el medio en que vive: su casa y su pueblo, con su familia y con el vecindario. Es como un constituir-se y llegar a ser desde su propio deseo y que se expresa desde un conflicto o confusión entre lo permitido y lo no permitido, entre lo posible y lo imposible, entre las normas impuestas y parece que un mundo ideal o utópico.

Sin embargo, Concha demuestra que es posible cambiar las cosas. Ello lo hace explícito a través de su propia transformación a lo largo de todas las entrevistas. Es la evolución, su llegar a ser y a posicionarse como mujer en el mundo, su propia creación libre, un recorrido por su ser a través del proceso de individualización de Concha. Para ello es importante su entrada al Centro Juvenil, a la Asociación de Mujeres de su barrio, y a la Asociación de Padres de Alumnos y Alumnas del pueblo. ¿Qué significa todo ello?

A nivel general todo se mueve en la necesidad intrínseca de Concha por llegar a ser y dar expresión libre a su identidad. Lo que pretende a nivel interno es tomar la palabra, reivindicando la situación que vive, lo que quiere, lo que siente, y como quiere vivir. Todo ello lo hace a través de estas estructuras, "permitidas" en su medio, y aprovecha este espacio para vivir una existencia más libre. En este sentido es importante la búsqueda de sí misma que Concha realiza a través de las demás mujeres con las que se relaciona en estas estructuras.

Mujeres que le van permitiendo conocer-se y a través de la mediación se crean proyectos, que para mí tienen el significado de político. No sólo porque intervenga en la política y aporte a ella en el contexto de la localidad, sino porque la entiendo como política de la relación, una relación femenina. Es como re-crear el lienzo de su vida, como comenzar a escribir un libro, como dar otro giro a la historia, haciendo visible lo que siempre ha existido y que ha sido rechazado. Es la toma de conciencia y la posición de Concha y las otras mujeres. Toda una creación de genealogía femenina, de lo que resalto el valor o importancia del ejemplo de Concha, de su palabra.

Ésta las saca de las formas de exilio sentidas por Concha. Por ejemplo, a través del Centro Juvenil Concha critica a la iglesia, aunque como ella expresa "lo vivo mal, porque parece que estoy en contra de mi madre". En ello puede observarse el conflicto que la sociedad patriarcal y un medio de represión le impone a Concha, obligándola a vivir reproduciendo las normas estipuladas sin dejar expresión a la libertad. A pesar de ello, Concha intenta explicar a su madre sus ideas, sus razones, sus sentimientos...

En este sentido pienso que es importante la relación de Concha con su madre. Es una relación de solidaridad, de ayuda, de comprensión, y aunque siga yendo a misa diaria porque ha sido socializada en ello y la sociedad de su tiempo la rechaza, la exilia si se aleja de estas normas, Concha tiene un papel muy importante con respecto a su madre y con respecto a las mujeres de estas generaciones y de generaciones venideras. Para mí Concha representa un cambio, una transformación, a partir de la creación de su identidad femenina y de su individualización.

LA ENTRADA AL MUNDO HETEROSEXUAL DESDE EL ORDEN PATRIARCAL

Desde los intentos de Concha por su libertad femenina, el sistema patriarcal juega en su contra. Concha se hace mayor, ha sido socializada con respecto a las normas de su tiempo, conforme a los cánones de la iglesia, pero el tiempo juega en su contra. Concha conoce lo que ella siente como un amor obligado. Me refiero a su entrada en el mundo heterosexual, un mundo obligado para la mujer adulta. De lo contrario Concha será rechazada de su sociedad, será mal vista, y vivirá un nuevo exilio: el de mujer soltera, que no ha llegado a cumplir su ideal de feminidad, que no ha llegado a dar hijos e hijas al patriarcado para que se retro-alimente y siga reproduciéndose.

Cuando conoce al que será su marido Concha, consciente o inconscientemente, transgrede las normas dentro de la respuesta que da a ellas. Por un lado, desde la obligatoriedad de una relación sexual con Manuel, intenta ver en él una vida más libre alejada de la casa paterna. Es su deseo de creación su propia identidad como mujer, de gozar de la libertad en un mundo que no la acepta. Sin embargo, esta huida que Concha a penas se atreve a expresar con palabras pronto se convierte en obligada por el exilio que sufre por parte de su propia familia.

De las relaciones sexuales mantenidas previas al matrimonio surgirá una nueva vida. Llegan con ello más rechazos para Concha, por haber hecho algo prohibido, que mancha su honra de mujer, y rompe el ideal de feminidad y represión creado por el patriarcado como único modelo femenino, como única posibilidad de existencia, no desde la libertad de opción, sino desde la obligatoriedad e imposición. Esto lo vive Concha de una forma muy curiosa, expresándolo a medias palabras al principio y con toda libertad al final del proceso de entrevistas, como "una violación, yo diría que fue una violación". Una violación en el sentido de hacer algo que ella no quería, pero Concha va más allá porque sintió las cadenas que la llevaban a ir en contra de su deseo, a ir en contra de lo que ella quería y de cómo se pensaba y planificaba su vida.

Y tiene sentido, porque a partir de aquí la vida de Concha cambió entrando en una cuesta abajo a toda velocidad para entregarla físicamente a un hombre al que se había dado, al que se había entregado, ¿pensando en qué? Algunas veces la propia confusión planteada por Concha confunde, pues plantea el tema de la desinformación, de la cultura y la socialización, del peso de la tradición, que lleva a las mujeres casi de 
forma inconsciente a repetir cánones y modelos por el rechazo, si no directo indirecto, oculto o no explícito, que se siente.

Casi ni se entera de lo que vive porque lo desconoce. Se sumerge en unas relaciones de dominación a través de su cuerpo, que engendra a Pedro. Da vida a un nuevo ser que significa mucho para ella, pero muy diferente para su pareja. Concha refleja la libertad desde la posibilidad de ser un dos y Manuel expresa sus deseos por vivir desde la posesión y el control de Concha, de algo que es suyo y que su sexo y privilegios patriarcales le han otorgado.

El peso de la tradición y la cultura: la construcción de un hogar y el obligado casamiento

La complejidad en la que Concha está inmersa la llevan a vivir en un mundo que se reproduce casi sin remedio. Es importante para ello tener en cuenta el medio contextual en que vive ella, así como las características de su familia y el peso que la cultura y la iglesia tiene. Ello explica que Concha se vea abocada a una inevitable reproducción, a un mundo que los demás le construyen. La identidad de Concha está en manos de su padre, quien la obliga a casarse antes de que su embarazo se le note y la gente del pueblo hable y critique.

"Lavar la honra de su hija", como la propia Concha expresa, es lo que quiere su padre. Para ello, para guardar el anonimato, para ocultar lo ocurrido, pues es una mancha en la familia, una oscuridad, un desorden divino y contranatural, un pecado Concha y Manolo se casan en la máxima soledad. A toda prisa su padre hace reformas en una casa de que dispone a la salida del pueblo para que sirva de hogar matrimonial. Concha manifiesta en este momento el más fuerte de los destierros.

Primero, ha de alejarse de la casa paterna por haber pasado al control de su marido, el cual dominará su vida, la guardará, hablará por ella y hasta le dirá lo que tiene que sentir. Ejemplo de este exilio que sufre Concha ha sido el control de su cuerpo y la maternidad en ella. Unido a ello, la casa que su padre le construye la ahoga aún más. Es un símbolo de encerramiento, de interiorización, de un mirar el mundo a través de la ventana, de ser receptora de la vida y del mundo, no actora de nada.

Está claro que Concha vive en la máxima de las exclusiones, que pueden resumirse en la obligatoriedad de un sistema social y político predominante de rechazarla de todo origen y de evitar a toda costa que tenga otro papel en el mundo que el de la mentira: utilidad social a través de la maternidad, del cuidado de la vida, del dar una nueva vida para la cadena de montaje consolidada.

El motivo del casamiento es para ella un nuevo exilio, un mundo que la rechaza por no cumplir su valor social y por haber hecho algo que no es permitido. Mantener relaciones sexuales y tener un hijo fuera del matrimonio no es posible en su mundo, porque ello es signo de control patriarcal. En ello no tiene cabida la diferencia sexual. Por tanto, Concha no tiene nada más que decir, sino vivir la vida que le toca vivir, la que los demás han decidido para ella y en su propio beneficio. Su marido controlando su cuerpo, con la intención de "tener" y "disponer" de una mujer que cumpla ese ideal de feminidad, de domesticación, creado en la época. Una mujer que sea buena esposa, buena madre y buena ama de casa, que le garantice una calidad de vida y una calidad de muerte, velando por él. El llanto, la hostilidad de las palabras, la oscuridad y el color negro hacen eco en la vida de Concha.

\section{La vida matrimonial, el papel de Concha en su familia, su maternidad}

Por tanto, la vida de Concha tiene un futuro marcado. Ser trabajadora en el hogar, madre de familia, cuantos más hijos e hijas tenga mejor, más ocupada estará en sus tareas y más alejada de todo cuanto tiene que ve con los espacios públicos y sociales. Es importante al respecto cómo Concha vive su maternidad, pues su marido tiene que salir fuera de la provincia por un tiempo para trabajar, obligado cumplimiento masculino, y ella vive su embarazo en la soledad. Esto tiene sus elementos negativos para ella, en la medida que siente que para su marido la maternidad -la vida que llega- significa algo muy diferente que para ella. La posibilidad de llegar a ser dos está en Concha y ella es la que le siente y crea vida. El valor de la diferencia no está en él, regido por un código patriarcal que forja día a día para que no se desgaste.

Sin embargo, esta negatividad la termina viviendo Concha como una posibilidad para auto-conocerse, orientarse, explicarse cosas... Es la posibilidad de disponer de unos espacios y de unos tiempos propios para la introspección. Asimismo disfruta de su maternidad, quizá visto en solitario desde un mundo patriarcal donde la gente de su alrededor siente tristeza por ella, pero en libertad. Son momentos muy disfrutados por Concha porque tiene la posibilidad de vivir en una casa sola con una vida dentro. Es una posibilidad para plantearse una existencia libre y replantearse su vida, todo ello desde el miedo que le siembre el regreso de Manuel a la casa. Y es entonces cuando se atreve a poner en práctica su ser mujer en el mundo.

\section{LA FUERZA DE LA RELACIÓN FNTRE MUJERES, UNA RELACIÓN DE AUTORIDAD}

En este tiempo de soledad goza de unos tiempos y unos espacios que le son propios. Estos los construye y los edifica como quiere. Para ello sirven de ayuda las mujeres que conoce a través de los centros en los que participa, en estos momentos, el Centro Juvenil y la Asociación de Mujeres en la que se inicia. Para ella significa un disfrute ponerse en relación con otras mujeres desde su estado maternal. La experiencia juega aquí un 
papel simbólico muy importante porque sirve como nexo de unión a las mujeres desde la diferencia sexual.

Me explico, desde lo que Concha vive y lo que ha vivido, desde el partir de sí de Concha, se pone en juego el partir de sí de las demás mujeres, desde las diferencias biográficas, contextuales, de vida que la caractericen. Pero el origen, el punto de partida de la relación es el mismo. Se comienza a establecer una importante red de mujeres, cuya relación se caracteriza por la solidaridad, la ayuda, la comprensión y el compromiso mutuo desde el entendimiento del amor. Es una madeja de lana o de hilo que cada vez contiene más material y cada vez toma más consistencia, fuerza y solidez. Una madeja difícil de romper o de desgastar.

Defino estas relaciones como relaciones de autoridad porque, a partir de la puesta en juego de los deseos femeninos, es posible dar respuesta a ellos desde el sistema de apoyo montado. En estos momentos el grupo de mujeres sirve de refuerzo a Concha y la impulsan para tomar decisiones, para dar rienda suelta a su vida, y para definir-se y nombrar-se en el mundo que quiere y conforme a lo que ella es y siente. El peligro que sigue azotando a Concha es el regreso de su marido, la vuelta al hogar, porque aunque ahora ella sigue viviendo en él lo hace desde su libertad individual, no desde el impuesto de vida patriarcal.

\section{El REGRESO DE SU MARIDO Y LA LLEGADA DE JULIA}

El regreso de Manuel significa una relativa vuelta a la "normalidad" patriarcal porque en todo estos meses la vida de Concha ha sufrido cambios, mejor dicho, la propia Concha ha comenzado a transformarse. Sin embargo, la toma de posesión de Concha se refleja en un nuevo embarazo cuando Pedro tiene a penas un añito y medio. Aunque ello signifique la dominación de Concha a través del cuerpo femenino, la llegada de Julia significa para ella la ruptura a este tiempo de guerra.

Primero, porque su vida la va siento como propia, aunque sea necesario dar continuidad a algunas costumbres, normas o elementos culturales impuestos para las mujeres y permitidos para los hombres en su sociedad. Poco a poco va tomando decisiones, va dando rienda suelta a su vida, a su imaginación. Accede a la formación, algo que había valorado desde siempre y de lo que las relaciones con su hermana son un ejemplo. Cursa diferentes talleres, actividades formativas, accede de nuevo al terreno laboral, lo que la dignifica y da un ejemplo a su marido, el cual se niega desde siempre que ella trabaje "porque no lo necesita". En definitiva, es capaz de romper con la división tan fuerte de roles y funciones a las que era sometida, así como de apropiación de espacios y tiempos que les pertenecen.
Todo ello se mezcla con el nacimiento de Julia, que tiene un valor simbólico diferente, no sólo porque Julia sea una niña, sino porque ella ha crecido internamente y su posición actual en el mundo desde su ser, sentir y actuar como mujer piensa que servirá a Julia a través de su ejemplo y de su palabra. "Yo no permitiría que hicieran con ella lo que han hecho conmigo" es la frase que Concha nos resalta en su discurso. Es la defensa de una madre por la imposición patriarcal y la anulación de identidad femenina. Ella se define como madre y como maestra de la vida de Julia.

UNA CONTRADICCIÓN VIVIDA POR CONCHA: OPRESIÓN DE UNA HUIDA OBLIGADA Y LIBERACIÓN QUE NO TERMINA DE SER

Situándonos en el presente que nos transmite Concha, éste se siente como libertad que no termina de ser real o completa, porque en su mundo siguen perviviendo los privilegios y normas de una sociedad patriarcal. Su vida se instaura entre la confusión y lo difuso de un medio en el que la realidad libre es explícita sólo en términos de subordinación y dominación femenina, en un mundo de dominantes y dominadas.

Ello se refleja en la división sexual del trabajo que sigue existiendo en la sociedad y en el mundo de Concha. Ella, aunque trabaja fuera del ámbito familiar -en contra de la voluntad de su marido- también recae sobre ella el peso de los trabajos reproductivos, relacionados con el cuidado de la familia, las tareas del hogar, la calidad de vida... Ello se une al obligado cuidado patriarcal de su madre. Digo obligado no porque ella quiera abandonar o no cuidar a su madre, sino porque ésta es una expectativa creada desde el patriarcado y que es impuesta en nosotras, siendo socializadas en ella.

El trabajo de la casa es interesante resaltarlo desde la división de roles de su marido y ella, así como de su hijo y de su hija. Concha se niega a que Julia reproduzca estos mismos valores, pues Pedro no lo hace, e insiste en su formación, en su autonomía como mujer y en su libertad. Recaen sobre Julia los deseos y expectativas anheladas de su madre, cuya relación es de apoyo, de lucha, de compromiso y de implicación femenina. Eh aquí el importante valor de las relaciones generacionales y la transmisión ideológica entre madres-hijas, abuelas-madres, o entre otras mujeres.

La relación de pareja la vive hoy día como su máxima confusión o conflicto. ¿Abandono o vida en constante guerra? Estas son las dos posibilidades que se plantea Concha. Es interesante cuando nos dice lo que pensaba antes de casarse y con respecto a su maternidad, pues ello nos lleva al comienzo y al sentimiento de la opresión femenina desde nuestra protagonista. Nos plantea sus pensamientos más internos, no conocía ni a su marido con el que lleva muchos años conviviendo: "yo pensaba: si no me viene la primera falta, no me caso con Manuel" "mi deseo era no estar embarazada en estos momentos, era algo que yo no había disfrutado, yo no lo quería" 
Este inicio de posesión y control masculino, así como de subordinación femenina y de incluir a Concha en una vida que no quería como suya es interesante para todo su desarrollo y en su estado actual. En ello se observa la evolución de Concha que nos transmite unaS relaciones obligadas y el entrar en una situación por el peso patriarcal y cultural sin ser consciente de ello. La desinformación a la que Concha, y mujeres como ellas han sido sometidas, la lleva a vivir una vida hecha primero por su padre, y más tarde por su marido, por lo que éste quiere hacer con su vida, utilizando como medio a Concha.

Sin embargo, la actualidad de Concha es diferente en la medida que su proceso de individualización ha sufrido una evolución. A ello han ayudado otras mujeres en las que ha intentado buscarse a sí mismas, les han servido de referentes, de ayuda para orientarse en un mundo de hombres en los que su identidad ha quedado anulada. Concha ha dado un paso importante, pero sigue viviendo conflictos, conflictos importantes facilitados por la sociedad patriarcal. Es la falta de autonomía de Concha, ya no mental y personal, sino económica, lo que la hace seguir dependiendo de su marido.

"Si yo encontrara un trabajo y tuviera dinero para vivir no sé si me plantearía dejar a Manuel". Con estas palabras de Concha finalizo este análisis sabiendo que en este trabajo no ha quedado reproducida totalmente su vida, sus sentimientos, sus vivencias; esto puede considerarse como un esbozo, que nos ayuda a comprender lo que ha vivido, pero muy diferente a lo que yo he sentido mientras ella lo contaba. Bien, esta frase la resalto significativa en la medida que sigue reflejando la confusión que vive Concha. Un sujeto femenino que se crea y se recrea, que avanza, pero que sigue encontrando impedimentos porque los esquemas mentales, culturales, económicos y políticos de su medios siguen siendo patriarcales.

Concha manifiesta la dependencia económica a su marido y la imposibilidad de mantenerse sola económicamente y mantener a sus hijos. Ello vuelve a sacar a la luz la división sexual del trabajo y el no reconocimiento de los trabajos que las mujeres han desarrollado a lo largo de su vida. Ésta es otra estrategia clara del patriarcado como medio de control y manipulación femenina. Ello lleva a Concha a desear acceder a un empleo que le permita su total independencia lejos de Manuel, algo que sabe que él nunca permitirá. Este miedo que refleja en su voz se traduce en la posibilidad que transmite en sus palabras, ese "no sé si me plantearía el abandono", que nos traduce el no sé si sería capaz de volver a transgredir una norma aún más fuerte.

\section{CONCLUSIONES}

La investigación realizada pone de relieve a través de la vida de Concha todo lo que es compartido. Las mujeres comparten situaciones y prácticas más allá de sus peculiaridades e idiosincrasia. Me refiero tanto a las prácticas sociales como a la interpretación de los hechos. Ello hace que los relatos en las entrevistas desarrolladas a menudo parezcan repetirse, aunque no son iguales. El origen es el mismo, al igual que nuestro punto para el análisis.

Entre mis inquietudes me planteo el motivo que lleva a la construcción del sujeto femenino y la validez de la transmisión oral como metodología. Es importante cómo en la relación entre mujeres se hace visible el exilio de una casa paterna en la que la diferencia sexual no tiene cabida, en la que la identidad femenina queda construida en base al patriarcado. Las opresiones de un medio de trabajo que no deja ser ni trabajar libremente desde la propia existencia femenina, además de la necesidad de situar-nos en este contexto siendo quienes somos y como cada es.

También se hacen visibles unas relaciones de pareja que necesitan construirse desde las relaciones asimétricas y el respecto a la diferencia, a quien cada uno es y lejos de prejuicios infundados. La genealogía femenina es importante: la figura de la abuela, de la madre de la protagonista, las relaciones generacionales, la transmisión cultural o ideológica, lo estipulado, lo marcado, lo prefijado. Se da importancia a la alfabetización como medio de libertad y la que yo le atribuyo a ello desde mi estudio y especialización laboral desde grupos de mujeres de clases más populares o desfavorecidas socialmente.

La vida de Concha es para mí un ejemplo de autoridad, una autoridad que reconozco a través de su palabra y de su transmisión oral. Es interesante porque a través de ello llegamos a comprender muchos de estos desórdenes simbólicos que las mujeres hemos vivido y seguimos viviendo muchas mujeres y a muy diferentes niveles. No obstante, en el fondo poseen la misma raíz porque -el dónde nos situamos- es una labor compartida entre todas nosotras. En este sentido, pienso que es interesante la creación de genealogía femenina y su valor desde la escritura o en otros aspectos de la vida, siempre considerando la diferencia femenina (pues los sexos son dos y como tales hemos de situarlos en el mundo) sea donde sea.

Este trabajo me ha sugerido también la necesidad de re-crear, de re-leer, en el sentido de situarnos desde otro orden, que manifiestan las autoras analizadas en sus ensayos o estudios, obras musicales, pinturas... en definitiva, la creación femenina, que nos transmite una existencia libre, bajo ese desorden simbólico desde el que las palabras de Concha, en un principio, parecían no tener sentido, parecían no decir nada. En eso también he visto una progresión. Al principio Concha parecía lanzar cosas sueltas, que tenían que ver con su vida, pero que estaban desordenadas. Al igual en mí, desde las respuestas a las preguntas que ambas hemos planteado a la otra.

Me ha parecido muy curiosa la relación que he establecido con Concha, la capacidad empática, nuestro entendimiento y comprensión mutua, y el saber de lo que hablaba 
la una y la otra a pesar de nuestras muchas diferencias de edad, de formación, de intereses, el escrito literal del discurso de Concha está repleto de "te entiendo" "puedo ponerme en tu lugar" "comprendo lo que puedes haber sentido" "es normal que hicieras eso en ese momento" "comparto situaciones o sentimientos parecidos"...

Es importante para mí la experiencia de Concha y este valor se lo otorgo también porque, en el fondo, habla de mí misma. Transmite muchas cosas que yo siento, muchos miedos, muchas inseguridades e incertidumbres, y quién sabe si busco en ella, en una mujer mayor que yo, el sentido de la experiencia, el querer adelantar acontecimientos, y el ver estrategias válidas utilizadas por Concha a lo largo de su vida. Esto es hablar del orden materno, en la medida que las palabras de Concha reflejan algo de mi vida, hablan también de mí misma, desde mi ponerme en relación-con-otra.

A partir de Concha se ha generado conocimiento y ello pienso que es importante en la medida que permite a otras mujeres entender-se. Ello crea genealogía femenina. También se han ido creando a partir de esa re-lectura de los discursos que he escrito significados nuevos. Esto ha sido así porque ha existido una implicación de ambas en un proyecto compartido de origen materno y con significado para ambas de creación propia.

He aquí el valor que le doy a la escritura como medio de expresar la palabra, el lenguaje femenino, a través de Concha, pero cuyo eco seguro llega a muchas otras mujeres. Concha nunca quedará en el olvido y la experiencia transmitida la siento como un proceso que se expande al mundo a través de mí y de las otras mujeres con las que yo me pongo en relación. Es la madeja a la que antes me refería, una red extendida en un medio que da cabida a la diferencia, una gran red que, en contra de la utilidad para cerrarla y capturar a los peces y a los delfines, también tiene otro sentido de apertura y de dejar ser y vivir libremente.

Éste es el modelo posible por el que Concha apuesta en su vida, un mundo diferente que de cabida a todas y a todos desde un dejar ser, dejar vivir, compartir, amar... Esto es lo más importante que me ha transmitido Concha a través de su sufrimiento, de su valentía, de su voz femenina y de su alegría e ilusión por vivir una existencia libre siendo mujer y situándose en el mundo como tal.

\section{REFERENCIAS BIBLIOGRÁFICAS}

Alonso, L.E. La mirada cualitativa en sociología, Madrid, Fundamentos, 1998

Bertraux, D., Histories de vie ou récit de pratiques? Méthodologie de l'approche biographique en sociologie, París, Informe al Éditions L'Age d'Homme, Lausana, 1976.
---, "De la perspectiva de la historia de vida a la transformación de la práctica sociológica", en J.L. Marinas y C. Santamaría (Coords.), La historia oral: métodos y experiencias, Madrid, Debate, 1993, 19-34.

Caballero, C., Magia: saberes y prácticas femeninas, Máster en Estudios de la Diferencia Sexual, Duoda. Centre de Recerca de Dones, Universidad de Barcelona, 2003-2004

Epiney-Burgard, G., Mujeres trovadoras de Dios. Una tradición silenciada en la Europa medieval, Barcelona. Paidós Ibérica, 1998.

Ferré, R., Las dos Venecias, México, Joaquín Motriz, 1992.

González Río, Ma J. Y San Miguel del Hoyo, B., “El método biográfico en el estudio de las desigualdades sociales", Revista internacional de sociología, no 33 (2002), pp.115-132 (cita página 117) Librería de mujeres de Milán. No creas tener derechos, Horas y horas, 1987.

Martín Gaite, C., Retahílas, Barcelona, Destino, 1974.

----, El cuarto de atrás, Barcelona, Destino Libro, 1978.

---, Desde la ventana, Madrid. Espasa Calpe, 1993.

----, El cuento de nunca acabar, Barcelona, Destino Libro, 1997.

Muraro, L., La verdad de las mujeres. En especial, lección 4. El entendimiento del amor, Máster en Estudios de la Diferencia Sexual, Duoda, Centre de Recerca de Dones. Universidad de Barcelona, 2002-2003.

Rivera Garreta, M., “Teoría Feminista. La escritura femenina. Un fantasma recurrente”, en especial, Tema 12, Máster en Estudios de la Diferencia Sexual, Duoda, Centre de Recerca de Dones. Universidad de Barcelona, 2003-2004.

----, Nombrar el mundo en femenino, Barcelona, Icaria, 1994.

Valera, E., Mujeres que leen, mujeres que escriben: Letradas en la Baja Edad Media (siglos XIII-XV), Máster en Estudios de la Diferencia Sexual, Duoda, Centre de Recerca de Dones. Universidad de Barcelona, 2003-2004. 